\title{
Predictors of Left Ventricular Remodeling after Aortic Valve Replacement in Pediatric Patients with Isolated Aortic Regurgitation
}

\author{
Sujatha Buddhe, MD, ${ }^{*}$ Wei Du, PhD, ${ }^{*}$ Henry L. Walters III, MD, ${ }^{\star}$ Ralph Delius, MD, ${ }^{*}$ and \\ Michael D. Pettersen, MD*广 \\ *Section of Pediatric Cardiology and Cardiovascular Surgery, Carmen and Ann Adams Department of Pediatrics, \\ The Children's Hospital of Michigan, Wayne State University School of Medicine, Detroit, Mich, USA; 'Department of \\ Pediatrics, Rocky Mountain Hospital for Children at Presbyterian St. Luke's Medical Center, Denver, Colo, USA
}

\begin{abstract}
A B S T R A C T
Objective. To identify the risk factors that could predict postoperative outcome after aortic valve replacement in pediatric patients with isolated aortic regurgitation (AR).

Background. There is controversy regarding the appropriate timing of surgery in asymptomatic or minimally symptomatic patients with isolated AR. In the pediatric age group, there are limited studies in this regard and most of them are on combined aortic valve stenosis and regurgitation.

Methods. All patients with biventricular physiology and morphologic left ventricle (LV) who underwent aortic valve surgery for AR from January 1988 to July 2010 were included in the study. Demographic, clinical, and echocardiographic data were collected at presurgical visit, early postoperative, 1 year, and most recent follow-up.

Results. Among 53 patients (36 males), 18 had LV end-diastolic diameter (LVEDD) $z$-score $>4$ standard deviation (SD) (group I) and 35 had LVEDD <4 SD (group II). Forty-one had long-term follow-up. Mean age at surgery was $11.6 \pm 5.9$ years; mean follow-up was $6.9 \pm 5.6$ years. Preoperative LVEDD $>4$ SD predicted persistent LV dilation $(>2 \mathrm{SD})$ at early post-op $(P<.05)$ and 1 year follow-up $(P=.09)$. Preoperative decreased LV function (fractional shortening $<28 \%$ ) was the only significant predictor of persistent LV dysfunction at most recent follow-up and requirement for repeat interventions $(P<.01)$. Most have reduction of $\mathrm{LV}$ dimensions in the immediate postoperative period to normal limits.
\end{abstract}

Conclusion. In children with AR, preoperative LV dysfunction and extreme LV dilation (>4 SD) are significant predictors of incomplete $L V$ remodeling or persistent $L V$ dysfunction.

Key Words. Pediatrics; Isolated Aortic Regurgitation; Aortic Valve Surgery; Predictors; Outcomes

\section{Introduction}

A ortic regurgitation (AR) results in volume overload and eccentric hypertrophy of the left ventricle (LV). Over time, chronic aortic insufficiency leads to LV dilation and dysfunction. ${ }^{1}$ Aortic valve replacement has been shown to improve hemodynamics in children with moderate to severe AR. ${ }^{2,3}$ The American Heart Association has published guidelines for the management of children with isolated AR. The indication for surgery is similar to that for adults, that is, New York Heart Association (NYHA) functional class III/IV symptoms, LV dysfunction (LV ejection fraction $<50 \%$ ), or progressive $\mathrm{LV}$ enlargement

Disclosures: None.

(C) 2012 Wiley Periodicals, Inc. (end-diastolic dimension $>4$ standard deviation (SD) above normal for body surface area and weight). ${ }^{4}$

Symptomatic patients need valve replacement irrespective of LV size. ${ }^{5,6}$ But there is still controversy regarding the appropriate timing of surgery in asymptomatic or minimally symptomatic patients. ${ }^{7}$ If the surgery is delayed until irreversible changes occur, potential benefits may not be achieved. However, if the surgery is performed early, it increases the possibility of a later operation especially in children who will experience physical growth. Better objective criteria are needed to predict postoperative $L V$ function and clinical outcome in these patients to make appropriate decision regarding surgical timing. 
There have been multiple studies in adults in an attempt to identify these risk factors, ${ }^{8,9}$ but most of the adult patients have other comorbid conditions including coronary artery disease, diabetes, and hypertension. In the pediatric age group, there are limited studies in this regard ${ }^{10}$ and most of the data in is on combined aortic valve stenosis and regurgitation. There is a paucity of data in the pediatric age group to determine optimal timing of surgery in patients with isolated AR. ${ }^{11}$

Our aim is to identify the risk factors that could predict postoperative outcome after aortic valve replacement in pediatric patients.

\section{Methodology}

This was a retrospective study conducted at the Children's Hospital of Michigan, division of pediatric cardiology. The study was approved by the institutional review committee at Wayne State University School of Medicine, Detroit Medical Center. The inclusion criteria were patients with biventricular physiology and morphologic LV who underwent aortic valve surgery for $A R$ from January 1988 to July 2010 at the Children's Hospital of Michigan. Exclusion criteria were patients with any other condition that could lead to volume or pressure overload on the LV including: (1) moderate to severe aortic stenosis; (2) moderate to severe mitral valve regurgitation; (3) moderate to large ventricular septal defect; (4) moderate or large patent ductus arteriosus; or (5) unrepaired coarctation of aorta.

All clinical, surgical, preoperative, and postoperative echocardiographic data and follow-up data were reviewed. The demographic and clinical data collected included patient's age, gender, ethnicity, height, weight, body surface area, and clinical manifestations. Echocardiographic parameters included left ventricular dimensions, LV function as measured by shortening fraction, and severity of $\mathrm{AR}$ as measured by the width of the regurgitation jet, the length of the regurgitation jet, and the severity of diastolic flow reversal in the descending aorta. Follow-up echocardiograms at the time of discharge from hospital, 6-12 months later, and at most recent follow-up were reviewed. NYHA functional class was determined according to symptoms and functional impairment at the time of preoperative evaluation regardless of previous symptoms and history. Surgical data collected included type of surgery, significant surgical findings, and complications. Operative mortality was defined as death occurring within the hospitalization period or within 30 days of operation.

All patients underwent prosthetic aortic valve replacement or Ross procedure based on the discretion of the primary cardiologist and the surgeon performing the procedure. The decisions regarding timing of surgery was made by the primary cardiologist. The surgeries were performed by four surgeons over the course of 22 years.

All echocardiograms were performed according to the American Society of Echocardiography recommendations. M-mode measurements of left ventricular dimensions and shortening fraction were obtained. $Z$-scores were then calculated using published normative data. ${ }^{12}$ In our study, similar to previous reports, $\mathrm{LV}$ end-diastolic dimension $\geq 4$ $\mathrm{SD}$ was considered to be extreme $\mathrm{LV}$ dilation. Patients were then divided into two groups based on preoperative left ventricular end-diastolic dimension; group I: patients with severe LV dilation (LV end-diastolic diameter [LVEDD] $\geq 4 \mathrm{SD}$ ) and group II: patients without severe LV dilation (LVEDD <4 SD). In the postoperative period, LV end-diastolic dimension greater than $>2$ SD was considered to represent persistent $\mathrm{LV}$ dilation. Shortening fraction $<28 \%$ was considered to represent $\mathrm{LV}$ dysfunction.

\section{Statistics}

This was a retrospective study. All data were reported as mean and SD for continuous variables and frequency for categorical variables. The two groups were compared using independent samples $t$-test, Mann-Whitney $U$-test, Fisher's exact, or chi-square tests depending on the distribution of the data. Within groups, comparisons of the changes in LV echocardiographic variables from preoperative to postoperative measurements were carried out using one-way analysis of variance for repeated measurements. All statistical analyses were performed using SAS software version 9.1 (SAS Institute, Cary, NC, USA). Multivariate analysis was performed to determine the significant variables predicting poor outcome. Statistical significance was defined as $P<.05$.

\section{Results}

A total of 53 patients underwent aortic valve replacement from January 1988 to July 2010 for isolated AR. Of these, 18 were included in group I and 35 in group II (Table 1). Twenty-eight (53\%) underwent aortic valve replacement (AVR) and 25 
(47\%) underwent Ross procedure. Mean age at surgery was $11.6 \pm 5.9$ years and mean follow-up time was $6.9 \pm 5.6$ years. The demographics are shown in Table 1. Although majority of patients were males, the age, weight, and sex distributions were not significantly different between the groups. There were more African Americans in group I.

The mean left ventricular end-diastolic and end-systolic diameters were significantly higher in group I as expected. Three patients in group II had $\mathrm{LV}$ dysfunction as measured by shortening fraction $<28 \%$. While none of the patients had significant symptoms, $48 \%$ had mild symptoms and there was no significant difference in number of patients with symptoms between both groups. There was no operative mortality in our patients. Only one patient died 4 years postsurgery due to non-cardiac-related events. During follow-up, all patients continued to be predominantly asymptomatic from a cardiac standpoint. Bicuspid aortic valve was the most common diagnosis as seen in $48 \%$ of the patients (Figure 1). Among them, $44 \%$ had balloon valvuloplasty and $21 \%$ had surgical valvotomy performed as primary procedure. Perimembranous or supracristal ventricular septal defect (VSD) leading to aortic insufficiency was the cause in $17 \%$, truncus arteriosus s/p repair with truncal valve insufficiency in $13 \%$, rheumatic fever in $8 \%$, and endocarditis was the etiology in $4 \%$ of patients (Table 2).

Table 1. Demographics, Clinical, and Echocardiographic Characteristics

\begin{tabular}{|c|c|c|c|}
\hline & $\begin{array}{l}\text { Group I } \\
(n=18)\end{array}$ & $\begin{array}{l}\text { Group II } \\
(\mathrm{n}=35)\end{array}$ & $P$ Value \\
\hline Age $^{*}$ & $11.4 \pm 4.1$ & $11.7 \pm 6.8$ & NS \\
\hline Weight $^{\star}$ & $50 \pm 31$ & $44 \pm 22$ & NS \\
\hline Male† & $11(61 \%)$ & $25(71 \%)$ & NS \\
\hline Caucasiant & $11(61 \%)$ & $29(82 \%)$ & .02 \\
\hline African American $\dagger$ & $7(39 \%)$ & $3(9 \%)$ & \\
\hline Symptoms $\dagger$ & $4(27 \%)$ & $13(38 \%)$ & NS \\
\hline Pre-op LVEDD* & $6.1 \pm 0.9$ & $4.9 \pm 0.9$ & $<.01$ \\
\hline Pre-op LVESD* & $4.1 \pm 1.3$ & $1.5 \pm 1.8$ & $<.01$ \\
\hline Pre-op LVESD >4 SD & $10(59 \%)$ & $4(11 \%)$ & .001 \\
\hline Pre-op fractional shortening ${ }^{*}$ & $38 \pm 5$ & $40 \pm 8$ & NS \\
\hline $\begin{array}{l}\text { Pre-op fractional shortening } \\
<28 \% \dagger\end{array}$ & $0(0 \%)$ & $3(8 \%)$ & NS \\
\hline LVEDV >4 SD† & $7(39 \%)$ & $10(28 \%)$ & NS \\
\hline AR jet/AV valve width $>0.5 \dagger$ & $8(44 \%)$ & $11(31 \%)$ & NS \\
\hline AR jet up to LV apex† & $6(33 \%)$ & $13(37 \%)$ & NS \\
\hline $\begin{array}{l}\text { Diastolic flow reversal: } \\
\text { severe } \dagger\end{array}$ & $5(28 \%)$ & $12(34 \%)$ & NS \\
\hline Follow-up $(y)^{*}$ & $8.7 \pm 4.5$ & $6.5 \pm 5.1$ & NS \\
\hline AVR† & $10(56 \%)$ & $18(51 \%)$ & NS \\
\hline Rosst & $8(44 \%)$ & $17(49 \%)$ & \\
\hline Prosthesis-aortic valve ratio & $0.96 \pm 0.06$ & $0.97 \pm 0.04$ & NS \\
\hline
\end{tabular}

${ }^{*}$ Mean \pm SD.

†Number (percentage).

\section{Outcomes}

Severe LV dilation was present in seven (13\%) patients at immediate post-op follow-up and eight (15\%) patients at 1-year follow-up (Figure 2). Pre-op LV dilation was the only significant predictor of persistent LV dilation (Table 3). Four of the $18(22 \%)$ patients in group I continued to have persistent $\mathrm{LV}$ dilation and four (11\%) in group II developed LV dilation later. Of the four in group II, two patients had moderate aortic insufficiency and two developed moderate mitral insufficiency that led to $\mathrm{LV}$ dilation.

Three patients (6\%) had LV dysfunction at the time of pre-op echocardiography and all of them were in group II. Two of these three patients continued to have persistent $\mathrm{LV}$ dysfunction at the most recent follow-up, while function improved in one patient more than a year later after initiation of inotropes. Another patient with normal pre-op function developed $L V$ dysfunction at most recent follow-up. This patient had significant comorbidities including developmental delay, kidney transplant, and development of severe mitral regurgitation later that led to significant $\mathrm{LV}$ dilation and dysfunction. This patient was scheduled for mitral valve replacement.

Repeat procedures were performed in 13 (25\%) patients. Of these, two required aortic valve and right ventricle $(\mathrm{RV})$ to pulmonary artery (PA)

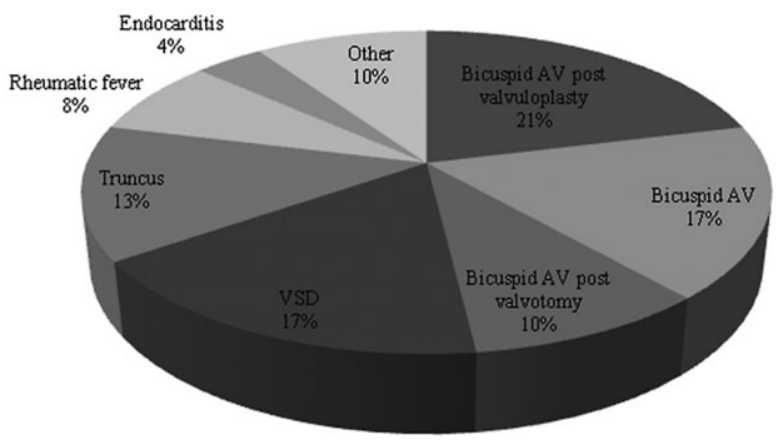

Figure 1. Etiology of aortic regurgitation.

Table 2. Etiology

\begin{tabular}{llll}
\hline & $\begin{array}{l}\text { Group I } \\
(\mathrm{n}=18)\end{array}$ & $\begin{array}{l}\text { Group II } \\
(\mathrm{n}=35)\end{array}$ & $P$ Value \\
\hline Bicuspid aortic valve* & $7(40 \%)$ & $18(52 \%)$ & NS \\
VSD* $^{*}$ & $3(18 \%)$ & $6(17 \%)$ & NS \\
Truncus* $_{\text {Rheumatic fever* }}^{*}$ & $3(18 \%)$ & $4(11 \%)$ & NS \\
Endocarditis* $^{*}$ & $2(12 \%)$ & $2(6 \%)$ & NS \\
Other* $^{*}$ & $1(6 \%)$ & $1(3 \%)$ & NS \\
\hline
\end{tabular}

*Number (percentage). 


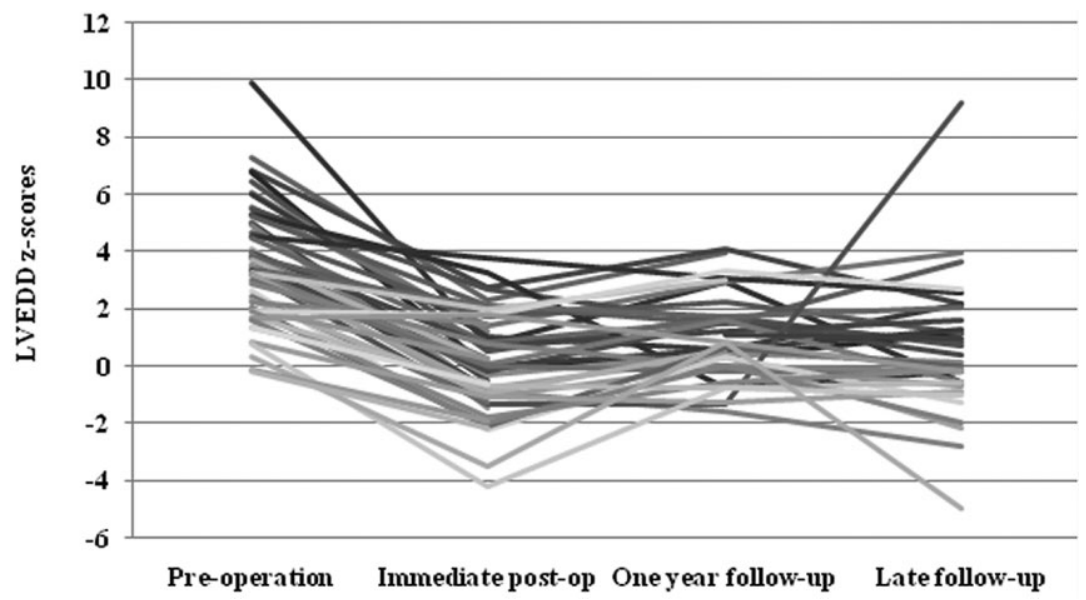

Figure 2. Graph showing trend of LVEDD z-scores.

Table 3. Outcomes

\begin{tabular}{|c|c|c|c|c|}
\hline Pre-op Echo Parameters & $\begin{array}{l}\text { Persistent LV } \\
\text { Dilation Post-op } \\
(\mathrm{n}=7)\end{array}$ & $\begin{array}{l}\text { Persistent LV } \\
\text { Dilation at } 1 \mathrm{y} \\
(\mathrm{n}=8)\end{array}$ & $\begin{array}{l}\text { LV Dysfunction } \\
\text { at Most Recent F/U } \\
(n=3)\end{array}$ & $\begin{array}{l}\text { Repeat } \\
\text { Interventions } \\
(n=13) \\
\end{array}$ \\
\hline Extreme LV dilation (LVEDD $>4$ SD) $(n=18)$ & $5(28 \%)^{\star}$ & $5(28 \%)(P=.09)$ & $0(0 \%)$ & $3(17 \%)$ \\
\hline LV dysfunction (LV SF <28\%) $(n=3)$ & $0(0 \%)$ & $1(33 \%)$ & $2(67 \%)^{\star \star}$ & $3(100 \%)^{\star *}$ \\
\hline LVESD >4 SD $(n=14)$ & $3(21 \%)$ & $4(28 \%)$ & $2(14 \%)$ & $4(28 \%)$ \\
\hline Symptoms $(n=17)$ & $1(6 \%)$ & $1(6 \%)$ & $0(0 \%)$ & $2(12 \%)$ \\
\hline LVEDV $>4$ SD $(n=17)$ & $1(6 \%)$ & $1(6 \%)$ & $1(6 \%)$ & $4(23 \%)$ \\
\hline AR jet/AV valve width $>0.5(n=19)$ & $1(5 \%)$ & $1(5 \%)$ & $1(5 \%)$ & $6(32 \%)$ \\
\hline AR jet up to LV apex $(n=19)$ & $2(11 \%)$ & $2(11 \%)$ & $1(5 \%)$ & $5(26 \%)$ \\
\hline Diastolic flow reversal: severe $(n=17)$ & $1(6 \%)$ & $2(12 \%)$ & $2(12 \%)$ & $6(35 \%)$ \\
\hline
\end{tabular}

${ }^{\star} P<.05 ;{ }^{* *} P<.01$.

conduit replacement, two required aortic valve replacement, two required conduit replacement, three required Melody valve placements, one required stent placement in an RV-PA conduit, two required pacemakers for post-op heart block, and one patient required Amplatzer device closure of para-aortic-valvular leak. No difference was noted in the requirement for repeat procedures based on the type of previous surgery: Ross procedure (24\%) and AVR (25\%). There was no significant difference noted between groups (Figure 3). Pre-op LV dilation was the only significant predictor of persistent $\mathrm{LV}$ dilation at post-op and 1 year follow-up echocardiogram. Pre-op LV dysfunction was the only significant predictor of persistent LV dysfunction and requirement for repeat interventions.

We also evaluated the effect of other echo parameters on outcomes. The number of patients with left ventricular end-diastolic volume $>4 \mathrm{SD}$, ratio of width of regurgitation jet to aortic valve $>0.5$, length of regurgitation jet up to $L V$ apex, and presence of severe holodiastolic flow reversal in the descending aorta was not significantly differ- ent between groups. None of these echocardiographic parameters had an impact on outcomes.

\section{Discussion}

The appropriate timing for aortic valve replacement has always been controversial in asymptomatic or minimally symptomatic patients with isolated chronic AR. This is particularly an issue in pediatric patients as they have growth potential and earlier surgery increases the chances of requiring a repeat surgery. As demonstrated in prior studies, our patients had a high rate of subsequent interventions after surgery for AR. ${ }^{13}$ Aortic valve replacement when performed in a timely fashion, even in children and young adults has been shown to offer good clinical outcomes and may lead to normalization of left ventricular size and function in most patients. ${ }^{11}$ However, surgery cannot be delayed too long after which the potential benefits of surgery are lost and the myocardial injury cannot be reversed. 


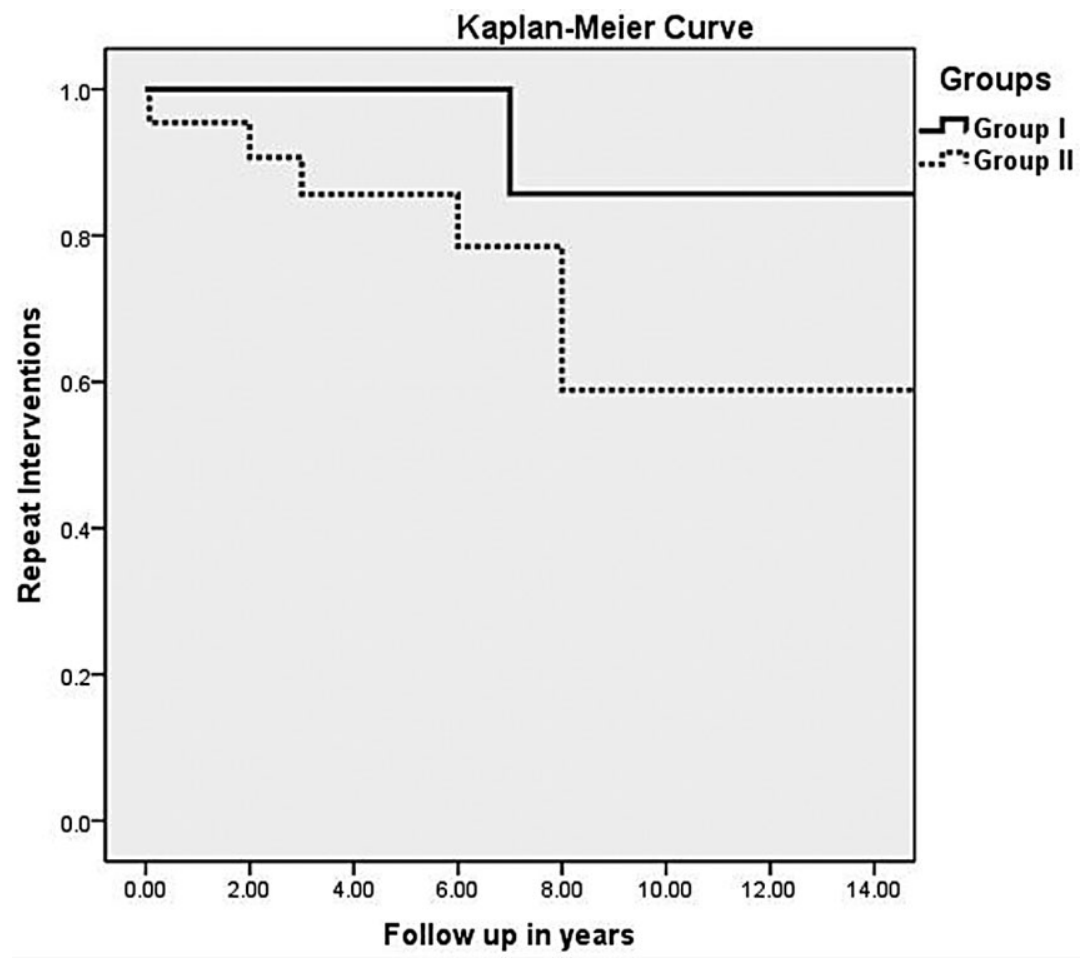

Figure 3. There was no significant difference in number of repeat procedures between groups.

The findings in our study are similar to previous studies in that severe left ventricular dilation is the predictor of persistent left ventricular dilation after surgery. ${ }^{10}$ In an adult study by Corti et al., a postoperative reduction in end-diastolic dimension of $>20 \%$ predicted a significantly better late survival, and echocardiography within 6 months postoperatively was able to enable additional risk stratification, regardless of preoperative findings. ${ }^{14}$ In our study, in patients in group I, the LV size improved immediately post-op in most of the patients to within normal limits with elimination of volume overload. Our findings are consistent with that of previous studies that severe LV dilatation is not an isolated abnormality and is usually associated with larger end-systolic dimension when compared with patients with smaller end-diastolic dimension. ${ }^{15}$

It was shown in previous studies that smaller indexed LV systolic and diastolic dimensions were associated with early restoration of LV systolic function. ${ }^{16}$ However, in our study, all three patients with reduced function preoperatively were in group II, and two of the three continued to have poor function. In other studies, late increases in ejection fraction usually occurred in patients who demonstrated an early significant increase in function, and late increase in function was unlikely to occur in patients with no change in ejection fraction during the first 6 months after operation. ${ }^{17}$ Although many patients with preoperative left ventricular dysfunction experience improved left ventricular performance after aortic valve replacement, performance does not always return to normal. ${ }^{18}$ In our study, too, all three patients failed to show any early improvement, and late improvement was seen in the third patient only after starting inotropes. Preservation of late ejection fraction was best if the operation was performed in patients with near-normal preoperative left ventricular function. ${ }^{9}$

In chronic AR, symptoms and LV systolic function were shown to be the main predictors for postoperative left ventricular dysfunction and extended long-term outcome after valve replacement. ${ }^{6}$ In our study, too, LV systolic function was the main predictor of poor outcomes, including persistent $L V$ dysfunction and requirement for repeat procedures. Our study had limited number of patients with systolic dysfunction pre operatively and postoperatively, so we could not better analyze its impact on clinical or echocardiographic outcomes. However, function continued to be normal even in patients with severe LV dilation. 
It is known that in the setting of severe AR, preoperative functional class III or IV symptoms are independent risk factors for excess immediate and long-term postoperative mortality. The presence of class II symptoms is also shown to be a strong incentive to consider immediate surgical correction of severe AR. ${ }^{5}$ In our study, none of the patients had significant symptoms. The presence of minimal symptoms however did not have any effect on persistent left ventricular dilation or dysfunction.

Our patient population had diagnosis similar to that expected in an American population with the majority being bicuspid aortic valve postsurgery or valvuloplasty. ${ }^{19}$ Many of our patients had previous surgical procedures $(40 \%$ surgical valvotomy, VSD repair, truncus repair) or catheterization (21\% balloon valvuloplasty) performed. The outcomes still have been favorable with no surgical mortality as shown in previous studies where mechanical AVR had excellent results in patients after previous repair of congenital heart defects in childhood, even in combination with complex concomitant procedures. ${ }^{2}$

It was shown in previous studies that other echo parameters can predict severity of $\mathrm{AR}{ }^{20}$ In our study, however, echo parameters including the width and length of the AR jet, severity of diastolic flow reversal in the descending aorta, and left ventricular end-diastolic volume did not predict outcomes.

It has been shown in adults that asymptomatic patients with normal left ventricular function have usually a good prognosis with a yearly mortality rate of approximately $0.04 \%$ and they develop left ventricular dysfunction at a yearly rate of $4 \%$. Approximately $50 \%$ of all patients are asymptomatic even after 10 years, ${ }^{21}$ and $\mathrm{LV}$ dysfunction and dilation may not progress concomitantly as seen in our study. In such patients with severe AR and moderate enlargement of the LV, regular check-ups should be performed to monitor the rate of progression of LV dilation and dysfunction. Surgery should be performed if the patient becomes symptomatic or develops deterioration of function. Surgery should be strongly considered if the LV $z$-score increases to greater than $4 \mathrm{SD}$. Our data suggest that in patients with normal LV function and no symptoms can be safely observed if their LV $z$-score remains $<4$ SD.

Stress echocardiography has been shown to be useful in evaluating pediatric patients after childhood Ross surgery for aortic valve disease. ${ }^{22}$ There is a role for probably using stress echocardiogra- phy in detecting the persistent LV remodelling/ dysfunction at follow-up after surgery in further studies.

\section{Limitations}

This was a retrospective study with a limited number of patients who had poor outcomes, so findings have to interpreted with caution. These are patients with diverse diagnoses, and the outcomes may be affected by the primary diagnosis. Twenty-two percent of patients were lost to followup. Also, the natural history and late survival could not be analyzed. Further multicenter prospective studies will be needed to validate these findings.

\section{Conclusions}

In asymptomatic or minimally symptomatic children and adolescents with chronic AR, preoperative severe $\mathrm{LV}$ dilation ( $>4 \mathrm{SD}$ ) is a significant predictor of persistent LV dilation (>2 SD). Preoperative decreased $\mathrm{LV}$ function is the only predictor of persistent systolic dysfunction and requirement for repeat interventions. Systolic dysfunction and $\mathrm{LV}$ dilation are independent predictors of outcomes and they do not necessarily progress concomitantly. Most of the patients have reduction of $\mathrm{LV}$ dimensions in the immediate postoperative period to within normal limits.

\section{Author Contributions}

Buddhe, Sujatha: Data collection and analysis, drafting article

Du, Wei: Statistics

Henry L. Walters III, Ralph Delius, Michael Pettersen: Concept/design, Critical revision

Corresponding Author: Sujatha Buddhe, MD, Pediatric Cardiology, The Children's Hospital of Michigan, 3901 Beaubien Blvd, Detroit, MI 48201, USA. Tel: (+313) 745-5993; Fax: (+313) 993-0894; E-mail: drbuddhe@gmail.com

Conflict of interest: None.

Accepted in final form: Fune 18, 2012.

\section{References}

1 Bonow RO, Lakatos E, Maron BJ, Epstein SE. Serial long-term assessment of the natural history of 
asymptomatic patients with chronic aortic regurgitation and normal left ventricular systolic function. Circulation. 1991;84:1625-1635.

2 Popov AF, Coskun KO, Tirilomis $\mathrm{T}$, et al. Mechanical aortic valve replacement in children and adolescents after previous repair of congenital heart disease. Artif Organs. 2009;33:915-921.

3 Kalavrouziotis G, Raja S, Ciotti G, Karunaratne A, Corno AF, Pozzi M. Medium-term results from pulmonary autografts after the Ross procedure in children and adolescents. Hellenic 7 Cardiol. 2006; 47:337-343.

4 Bonow RO, Carabello BA, Chatterjee K, et al. 2008 Focused update incorporated into the ACC/AHA 2006 guidelines for the management of patients with valvular heart disease: a report of the American College of Cardiology/American Heart Association Task Force on Practice Guidelines (Writing Committee to Revise the 1998 Guidelines for the Management of Patients With Valvular Heart Disease): endorsed by the Society of Cardiovascular Anesthesiologists, Society for Cardiovascular Angiography and Interventions, and Society of Thoracic Surgeons. Circulation. 2008;118:e523-e661.

5 Klodas E, Enriquez-Sarano M, Tajik AJ, Mullany CJ, Bailey KR, Seward JB. Optimizing timing of surgical correction in patients with severe aortic regurgitation: role of symptoms. $7 \mathrm{Am}$ Coll Cardiol. 1997;30:746-752.

6 Turina J, Milincic J, Seifert B, Turina M. Valve replacement in chronic aortic regurgitation. True predictors of survival after extended follow-up. Circulation. 1998;98(19 suppl):II100-II106; discussion II6-II7.

7 Cheitlin MD. Finding "just the right moment" for operative intervention in the asymptomatic patient with moderate to severe aortic regurgitation. Circulation. 1998;97:518-520.

8 Enache R, Antonini-Canterin F, Piazza R, et al. Long-term outcome in asymptomatic patients with severe aortic regurgitation, normal left ventricular ejection fraction, and severe left ventricular dilatation. Echocardiography. 2010;27:915-922.

9 Brown ML, Schaff HV, Suri RM, et al. Indexed left ventricular dimensions best predict survival after aortic valve replacement in patients with aortic valve regurgitation. Ann Thorac Surg. 2009;87:11701175; discussion 5-6.

10 Tafreshi RI, Shahmohammadi A, Davari PN. Predictors of left ventricular performance after valve replacement in children and adolescents with chronic aortic regurgitation. Pediatr Cardiol. 2005; 26:331-337.

11 Arnold R, Ley-Zaporozhan J, Ley S, et al. Outcome after mechanical aortic valve replacement in children and young adults. Ann Thorac Surg. 2008; $85: 604-610$.
12 Pettersen MD, Du W, Skeens ME, Humes RA. Regression equations for calculation of $\mathrm{z}$ scores of cardiac structures in a large cohort of healthy infants, children, and adolescents: an echocardiographic study. 7 Am Soc Echocardiogr. 2008;21:922-934.

13 Karamlou T, Jang K, Williams WG, et al. Outcomes and associated risk factors for aortic valve replacement in 160 children: a competing-risks analysis. Circulation. 2005;112:3462-3469.

14 Corti R, Binggeli C, Turina M, Jenni R, Luscher TF, Turina J. Predictors of long-term survival after valve replacement for chronic aortic regurgitation; is M-mode echocardiography sufficient? Eur Heart 7. 2001;22:866-873.

15 Michel PL, Iung B, Abou Jaoude S, et al. The effect of left ventricular systolic function on long term survival in mitral and aortic regurgitation. $\mathcal{F}$ Heart Valve Dis. 1995;4(suppl 2):S160-S168; discussion S8-S9.

16 Cho SH, Byun CS, Kim KW, Chang BC, Yoo KJ, Lee S. Preoperative indexed left ventricular dimensions to predict early recovery of left ventricular function after aortic valve replacement for chronic aortic regurgitation. Circ 7. 2010;74:23402345.

17 Carabello BA, Usher BW, Hendrix GH, Assey ME, Crawford FA, Leman RB. Predictors of outcome for aortic valve replacement in patients with aortic regurgitation and left ventricular dysfunction: a change in the measuring stick. $7 \mathrm{Am}$ Coll Cardiol. 1987;10:991-997.

18 Hwang MH, Hammermeister KE, Oprian C, et al. Preoperative identification of patients likely to have left ventricular dysfunction after aortic valve replacement. Participants in the Veterans Administration Cooperative Study on Valvular Heart Disease. Circulation. 1989;80(3 pt 1):I65-I76.

19 Sadee AS, Becker AE, Verheul HA, Bouma B, Hoedemaker G. Aortic valve regurgitation and the congenitally bicuspid aortic valve: a clinico-pathological correlation. Br Heart 7. 1992;67:439-441. PMCID: 1024882.

20 Chin CH, Chen CH, Chen CC, Chen TH, Chang $\mathrm{ML}$, Chiou HC. Prediction of severity of isolated aortic regurgitation by echocardiography: an aortic regurgitation index study. $7 \mathrm{Am}$ Soc Echocardiogr. 2005;18:1007-1013.

21 Mandinov L, Kaufmann P, Hess OM. Diagnosis and indication for aortic valve replacement in asymptomatic and symptomatic patients with aortic regurgitation. Herz. 1998;23:441-447.

22 Pauliks LB, Brian Clark J, Rogerson A, Dipietro A, Myers JL, Cyran SE. Exercise stress echocardiography after childhood ross surgery: functional outcome in 26 patients from a single institution. Pediatr Cardiol. 2012;33:797-801. 